\title{
Developing Digital, Computational and Social Competencies through Investigative On-Line Activities
}

\author{
Zoltan GALIK, Ivan KALAS \\ Department of Informatics Education, Comenius University \\ Mlynska dolina, 84248 Bratislava, Slovak Republic \\ e-mail:galik@fmph.uniba.sk,kalas@fmph.uniba.sk
}

Received: August 2009

\begin{abstract}
Internet and its services have become inherent element of the lives of young people. Nevertheless, we observe that educational potential, which the Internet offers for supporting learning processes, is acknowledged and exploited only partially. On that account, for several years we have been involved in developing investigative on-line activities, highly popular interactive events among students of the Slovak schools. In this way, as a value-added benefit, we have created unique opportunity for us to study how students behave when solving problems in the technology enhanced learning situations, how they communicate and cooperate in the teams, which competencies they cultivate. For such educational research, we have made use of the thoroughly projected combination of the intervention design and qualitative non-participant unstructured observations - within the framework of the design-based research methodology.

In this paper we present our initial assumptions and inspirations, methods of our research work and major observations, we clarify what investigative on-line activities are and how we have collected and analyzed data obtained by observing students while solving the investigative tasks. In our research we have focused on the development of three classes of competencies, namely digital competencies (i.e., those that pertain to the area of general digital literacy), computational competencies (i.e., those that correspond to the goals of informatics in education) and social competencies (i.e., those that allow students to communicate, cooperate, create or evaluate their own doings, learning etc.). In our paper we present corresponding observations and also attitudes and reactions of the teachers - who have been involved merely as supervisors, not as members of the teams. We also summarise potential contribution of our investigative on-line activities to education in the modern society.
\end{abstract}

Keywords: investigative on-line activities, digital literacy, computational and social competencies, design-based research, peer-to-peer collaborative learning, TEL - technology enhanced learning.

\section{Introduction}

In their everyday lives, 12 to 18 year old students commonly take advantage of various services provided by the Internet. Yet, we believe that the utilization of educational potential of the Internet remains considerably unappreciated and unexploited. Therefore, we decided to design and develop a series of investigative on-line activities - fictitious 
criminal cases that would subsequently be solved by Slovak student teams for several hours each (within one day). Students-detectives communicated intensively during the investigation within the teams but also on-line with fictitious police headquarters from where they were receiving a range of tracks and clues - sometimes slightly misleading, imperfect, sometimes partly damaged - but always such that they could advance in investigation only if certain digital technologies were involved in a creative way.

These activities and corresponding research has yielded many interesting observations about how teams of students work together in common digital environments, how they cooperate when solving ill defined tasks, how they communicate and learn new strategies etc. In our research, we decided to concentrate on observing the growth of competencies to collaborate and solve problems in a team when being engaged in a sequence of investigative on-line activities, the development of their digital literacy and computational competencies, which contribute to the goals of informatics as a relevant pillar of general education. Our approach has productively combined progressive development of attractive on-line learning environments, which can be classified as educational interventions, see for, e.g., (Cobb et al., 2003) or (DBR Collective, 2003), with qualitative educational research. To do so, we were inspired by the design-based research methodology, which adopts interwoven structure of theoretical research for better design of educational interventions and iterative design of interventions for efficient educational research, see (Mor and Winters, 2007) or (Wang and Hannafin, 2005).

When designing and developing our investigative on-line activities we had been inspired by several outstanding projects, which we will highlight in Section 2.1. Beside this, we were stimulated by recent outcomes from educational psychology, which have proved that by playing games children develop new types of cognitive skills, see, e.g., (Tapscott, 1997). These can be summarized as:

- parallel information processing,

- efficient and prompt processing of the graphic (visual) information,

- experimental approach to problem solving,

- active involvement in searching for solutions,

- imagination and creativity development,

- accepting technologies as an ally.

Therefore, when designing our interactive investigative activities we have engaged the form of the games - each investigation is a playful incident with a goal to stimulate students-detectives to:

- communicate and cooperate within their teams - such phenomena are often suppressed in traditional educational systems and situations. On the contrary, in most of the games children are expected to communicate and cooperate, to solve problems by joint effort. Moreover, the players often have to present, explain and advocate their decisions and taken steps,

- solve problems - children engaged in a play hardly realize how much and how efficiently they learn,

- develop logical mind and mathematical thinking - in many games children are faced with tasks which require computations or logical inference, 
- employ various digital technologies as supportive means for performing cognitive operations and skills listed above.

In our design, development and implementation of the investigative activities we have also been stimulated by the recent research findings about productive possibilities to integrate computer games into the learning processes. Other stimuli came from the PISA ${ }^{1}$ and TIMSS $^{2}$ extensive research programmes. The overall scoring of Slovak students was less than satisfying and we had been thinking about possible strategies for remedy. One of them was improved pre-service teacher development ${ }^{3}$; another one was an effort to better understand the reasons of those phenomena.

Our investigative activities can thus be classified as computer games, although they have several specificities. Among similarities, we can consider their format, types of cognitive operations and level of motivation. We strived to develop efficient opportunities for supporting learning processes and collaboration of young people and through such interventions better understand educational potential of the Internet and interactive on-line activities for learning. In Section 2 we characterize in detail our inspirations and previous experience, we clarify what investigative on-line activities are and which research methods we have applied to collect and analyze data. In Section 3 we present various categories of the tasks, which students had to perform and we document facts and events that we observed in their doings and relations. We explore in detail three classes of competencies, the development of which we considered the most evident. In Section 4 we present the reactions and concluding evaluations of the teachers. We also summarize the most significant observations and findings.

\section{Investigative On-Line Activities}

Since 2000, we have been involved in designing, developing and organizing our investigative on-line activities. At that time, we started to reflect more deeply and thoroughly on the Internet and its educational potential. We formed our early assumptions about implementations of those activities into modern cognitive processes and about attractive and efficient ways of using the Internet. As an initial assumption, we took general model of using Internet in schools. We also adopted the theory of constructionism as our research platform; see (Harel and Papert, 1991). While examining those introductory stimuli we started developing our first concepts of activities as interventions into the process of exploiting computer networks. From there we gradually moved to a position, which indicated that educational on-line interventions could be exploited for fostering learning, developing digital literacy and further developing students' problem solving skills.

\footnotetext{
${ }^{1}$ See www. pisa. oecd. org.

${ }^{2}$ See nces.ed.gov/timss/.

${ }^{3}$ We are deeply engaged in this field, see, e.g., (Kalas and Winczer, 2008).
} 


\subsection{Initial Assumptions and Inspirations}

After we designed and developed several initial activities, we conducted a thorough search for similar projects and activities on the Internet. We were in quest for inspiration, related research findings, similar experience and new inspiring ideas for our activities. Thus, we managed to collected many highly interesting thoughts, which we subsequently tried to incorporate in our goals and strategies for developing digital literacy of students.

Highly inspiring for us was the activity called Superhighway Patrol ${ }^{4}$. Its origins go back to mid 1980s when David Cassey, one of the leading organisers of the project, was a schools' liaison officer for the Cambridgeshire Police, UK. When David was introduced to an early e-mail system, he immediately spotted an opportunity for police officers to communicate with schoolchildren by using this new medium. As a reaction, he started running a series of Ask the Police days in which children in those few schools that used e-mail in those days could send questions to police officers and received live e-mail answers. As the Internet expanded and made e-mail an everyday matter, David's idea grew into an activity called Superhighway Patrol in which a series of e-mails were being sent to schools about an unfolding story - usually a crime, sometimes a road traffic accident, a fire or other incident. As the story revealed more and more details, the students could e-mail questions to police officers in the central office.

At that time, the idea of the Superhighway Patrol activities was the most inspiring for us. As far as our goal was to combine the Internet with an external activity, the idea of solving an on-line mysterious case proved to be exceptionally suitable for us. In Superhighway Patrol, the students were learning about the work of police and trying to help solving real life problems without realizing that they were learning at all. We tried to transform this idea of unnoticed learning into the digital world and into the process of developing digital competencies of students. At the same time, we were also inspired by the story itself, so we profiled our activities as detective stories and mysteries. The students' motivation to solve problems (and thus to learn) was considerably increased by setting our stories into criminal situation.

Another valuable stimulus came from the famous and widely successful Dudley Challenge ${ }^{5}$. This on-line activity aimed at developing children's knowledge in several areas of learning (like history, geography, music, arts etc.). A balloon flying over Europe was simulated in the game. It was landing on different places - children's assignment was to find the exact position of landing. In order to do so they got in hand various methods of work: they had to collaborate in teams and (asynchronously) communicate with the organizers. Each single task of the activity was accessible for several weeks.

The Dudley Challenge was inspiring for us mostly because of the collaboration, which children were encouraged to adopt during the activity and because of learning together in groups, see (Lambert, 2002). We decided to foster the same learning strategy in our investigative on-line activities - students would have to collaborate in small teams during

\footnotetext{
${ }^{4}$ See www . net-detectives. org (2005) or www . logo . com/newsletter/7/ netdetectives.html (2009).

${ }^{5}$ See www . edu. dudley.gov.uk/c2 000 / europa / cEuropa/index.html (2009).
} 
the activity and learn new skills and new strategies while using the Internet for communication with organizers (and within their own teams). At the same time, they would be highly motivated to solve the problems because of competition with other teams.

Another influential and inspiring event is being organised in Hungary, namely the TeaM Challenge ${ }^{6}$, see (Rethey-Prikkel and Turcsanyi-Szabo, 2003). Unlike Dudley Challenge, the organizers of the TeaM Challenge do not provide any resources or pre-collected information sites. Instead, they present the contestants with more complex, natural and contextualised problems and urge them to search within the entire Internet. They also encourage the participants to use printed or electronic resources found at their homes, in libraries or collected through e-mails. As an outcome of that, the tasks require highly creative approaches from the students and the activities become more real-life and natural. The authors of the tasks want to confront groups of young people with effective, attractive and reasonable ways of using web, finding facts and cultivating their problem solving skills. As a side effect, they want young people to experience effective teamwork.

The TeaM Challenge was highly motivating project for us mainly because of its informatics view on the problem solving and searching for information on the Internet. Thanks to that project, in our investigative on-line activities we also focused on cultivating students' digital literacy through solving problems on the Internet.

\subsection{Sherlock Holmes On-Line}

Benefiting from the goals and approaches of the projects mentioned above and combining them with our own ambitions to adapt the on-line activities into the learning process we designed, developed and performed our own investigative tasks. We named them Investigations with Sherlock Holmes. We decided to aim this project of investigations at the students between 12 and 18 years. We created our own website with attractive design of mysteries combined with the personality of Sherlock Holmes.

Usually in two week period we announced through our website and run an interesting investigation - altogether 11 times. The primary goal of these activities was to find a fictitious offender who had somehow broken the law. Besides finding the criminal (or a group of criminals) students had to solve many additional problems somehow related to the investigation. These extra tasks were usually real-life problems. In order to solve them, wide spectrum of students' digital skills and competencies had to be involved. The start and timing of investigation was always announced long time before the activity, which by itself took about two and a half hour.

Students were solving the problems through the active communication with fictitious police headquarters (i.e., with us, the organizers). The teams communicated with us through e-mails or in a case of any technical problems they could use the discussion forum. Each activity started with an initial e-mail sent to participants around 2:00 p.m. Students had to open the investigation based on the initial instructions form the activity's introductory message. They did not know the problems to be solved later during the investigation before the actual start of the activity.

\footnotetext{
${ }^{6}$ See http: / / kihivas.ini.hu (2009).
} 


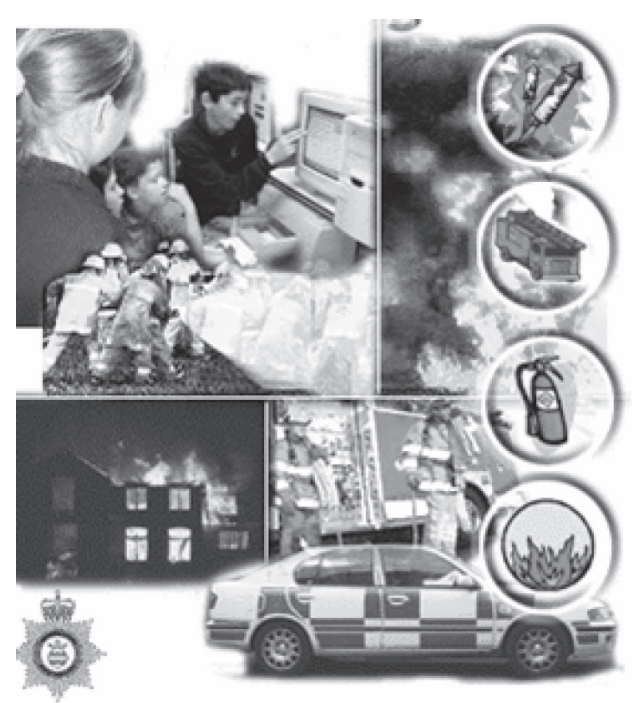

Fig. 1. Invitation to the upcoming investigation on the Sherlock Holmes portal in 2007, see www. sherlock-holmes.sk.

The teams worked mostly in schools and consisted of 4 to 6 students. After the initial e-mail, they were receiving more information concerning the investigation every 5-10 minutes. The messages from the headquarters were published also on the website of the activity. Those were not simple text e-mails, they often contained various additional information with the aim to move forwards the investigation. However, the messages sometimes also contained information, which was not relevant to the case and was meant to distract their investigation and make it more real.

During the investigations the students employed Internet with all its tools and services - for searching for information with searching engines (like Google, Yahoo etc.); sending e-mails (to communicate with the organizers and peers); communicating through various communication channels (like Skype, ICQ etc.); tracking the criminals on the Internet maps; examining and confirming the statements of the suspicious persons (e.g., by checking the on-line timetables); using small computer games (programmed by us), which helped them move the investigation or get a new insight into the observed matter. The investigation concluded with an assessment of all the gained points for every team. We then announced the most successful ones. During the evaluation, we analysed the partial results of every sub task. We also took into account the amount of time each team used to solve the case.

\subsection{Applied Research Methodology}

We assume that every active and creative usage of the Internet means cultivating one's digital literacy. However, present perception of digital literacy is rather narrow and naïve, it is often identified with being able to run the computer, open a browser and search 
for certain piece of information, send an e-mail etc. We do not consider this to validate that such person is capable of effective use of higher cognitive potential of the Internet. Therefore, one of the main goals of our research work was to thoroughly project, develop and explore the possibilities of using the Internet in the educational processes in more effective and more attractive ways.

Therefore, we decided to organize a series of investigative on-line activities. We wanted to collect clear evidence for stating that Internet was a suitable tool for developing digital literacy and problem solving competencies for real life. We also wanted to find out, whether the Internet activities could have positive contribution to students' complex mental development.

In our project we used the following qualitative strategies for data collection and researching:

- non-participant unstructured observations of the process of investigative on-line activities,

- analysis of the video records from investigations of one particular team,

- interviews with the participants,

- design-based research methodology to productively intertwine designing learning opportunities and building the theory of integrating Internet into modern learning processes, see (Cobb et al., 2003) or (DBR Collective, 2003).

When we started collecting our data, we believed that analyzing video records of the classroom had been well-documented and established research method. This conviction however did not fully prove at that time and we had to iteratively create our own technique for how to analyze dozens of hours of video records, what to observe, what to conclude and how to verify it by using other, complementary research methods.

To better meet our research goals we decided to observe in detail one of the students teams - namely, the F.B.I. team during their investigations. We decided to choose this particular team for several reasons: its members' age was between 13 and 14, which matched the average age of all participating students. In addition, the location of the school was suitable for us, not being too distant from our department. Before the investigative activities started, we made sure that the team members had appropriate (i.e., average) skills in using computers. We created suitable environment for them to do the investigations at our department's computer room. Every team member had his or her own computer connected to the Internet. During the activity we took a video record of their collaborative work. Prior to each investigation, we conducted an interview with each member of the team. After the end of the activity, we again conducted another interview with them about the investigation: we asked them how they liked the activity, how they cooperated, what they learned etc. In addition to the interviews with the F.B.I. team, we also performed interviews with four other teams.

Essential source of data for our research on investigative on-line activities was analysis of the video records. We evaluated collected video data without any automatic or semiautomatic pre-processing. We were interested in various human factors occurring during the activities: how students collaborated and communicated during the investigation; how they exchanged information; how they solved problems collaboratively and 
together as a group. At the same time, we also tried to look at the students' work from the informatics education point of view. We were creating new approach to developing students' digital literacy. Unfortunately, this research area is not well understood yet so we are not able to compare the efficiency our approach with other methods of developing the digital literacy.

\section{Tasks, Skills and Observed Performance}

To reach our main goal, which was to better understand what educational potential the Internet offers and how to utilize it to support the cognitive process, we designed, created and conducted series of investigative activities. These activities consisted of several complex tasks, usually constructed of vaguely defined, open-ended sub-problems. We observed the participants, we took records and analyzed what kind of social and cognitive skills they performed while solving those tasks. In this chapter we will analyze different categories of given tasks and document the phenomena, which we discovered during the process of problem solving. We will present particularly those findings, which we observed and evaluated as significant in terms of improvement of wide spectrum of important competencies for modern education, for learning in digital world and in the creative society ${ }^{7}$. We focused on three areas of competencies, namely: (i) competencies constituting digital literacy; (ii) computational competencies, which we consider key factors in the area of informatics education; and (iii) social competencies, in particular communication, collaboration, creativity and metacognitive competencies - including thinking about the problem, planning the problem solving process and splitting it into smaller sub tasks; assessing one's own abilities and assessing abilities of other members of the team.

We used three different sources to collect data about social and cognitive processes of the students occurring during investigations:

- Detailed and systematic non-participant observations of one particular team of students. For this purpose, we video recorded all of the F.B.I. investigations. This team had good or average results in their performance, see Table 1.

- Extensive communication with all teams and team members - prior to investigations, during them and afterwards. We collected and analyzed their comments, reactions and attitudes.

- Apart from young investigators we intensively concentrated on communication with the teachers who supervised the teams, although they did not interfere into the work of their students, they neither organized the teams, nor managed the problem solving processes, nor evaluated their findings and conclusions. The complete collaboration - if it emerged in the team - had to be initiated and managed by the students themselves.

\footnotetext{
${ }^{7}$ We are inspired by M. Resnick (2007): Success is based not only on what you know or how much you know, but on your ability to think and act creatively. In short, we are now living in the Creative Society.
} 
Table 1

Profile of the F.B.I. team

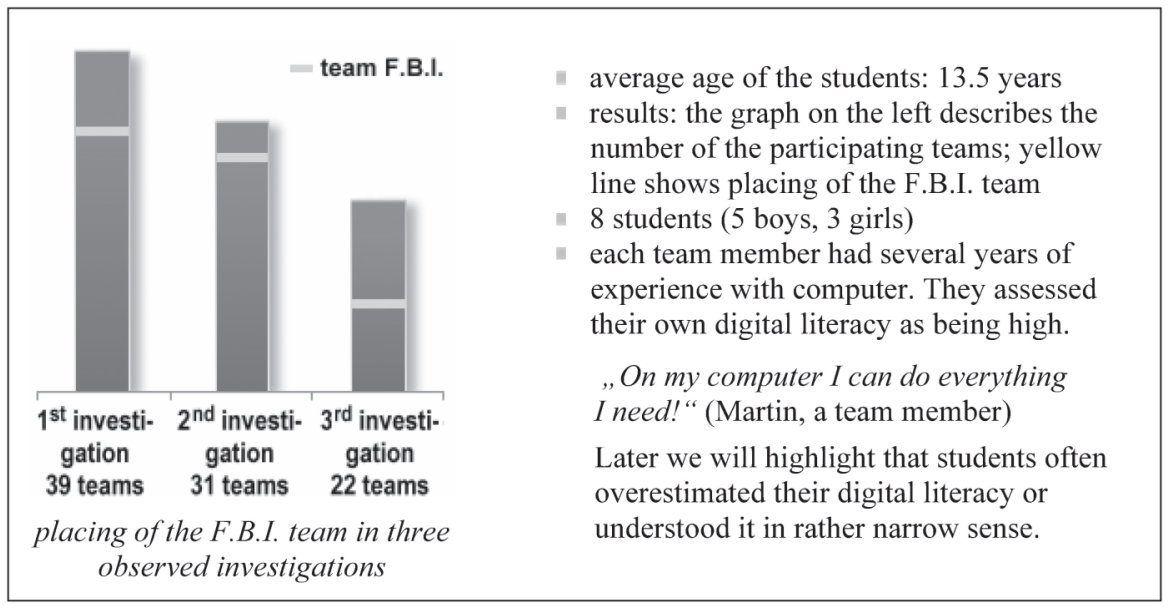

During the data collection, we strived to record the investigation methods of the team, the way of their collaboration within the team, but also with the headquarters (i.e., with us, the organizers). Next to this, we documented the use of different software tools and other digital technologies. We also wanted to notice any possible progress in skills and performance, the development of digital literacy and informatics knowledge of the students. We managed to do this thanks to systematic observations of the same team during several investigative activities.

\subsection{Digital Literacy}

In our research work we interpret and implement digital literacy ${ }^{8}$ (and digital citizenship) as a complex of abilities

- to select and apply adequate digital technologies to locate or create, understand, interpret, process and use information in multiple formats from a diverse range of digital sources,

- to perform tasks effectively in a digital environment,

- to critically evaluate and apply new knowledge gained from digital environments,

- to collaborate in solving problems and present, share and communicate solutions obtained in and through digital environments,

- to understand social implications (including safety, privacy and ethics) emerging from digital culture.

We assume and our research validates that it is possible to foster the development of digital literacy and digital citizenship of the students by thoroughly selected sequences of attractive on-line and off-line activities. Solving these activities and tasks require applying

\footnotetext{
${ }^{8}$ Based on (Uni2010, 2006; Jones-Kavalier and Flannigan, 2006; Kalas and Tomcsanyiova, 2009; Gilster, 1997) and others.
} 
different cognitive operations, abilities, techniques and processes. Effective exploitation of digital technologies requires deep understanding and knowledge of many different concepts, skills and techniques - much more, than we would expect at a glance ${ }^{9}$.

In the course of investigations, the students were making use of various services of the Internet. In particular, they were communicating, searching for information and evaluating their findings from the Internet (e.g., departures of the trains and buses, tracing the locations of the suspicious persons on the Internet maps, downloading pictures and sounds and more). To be able to perform all those operations, the participants needed to have the appropriate level of informatics' knowledge; for example, they must have used the graphic and sound editors to analyze the negative of a bitmap or to analyze a sound etc. We were pleased to observe how quickly and relatively independently they were able to employ new technologies and unknown software applications. For example, they received a coding program from us with only laconic help and had to use it immediately to decode a secret message.

On the following pages we will present our findings and observations (both positive and negative) of our research made on investigative on-line activities. The observations document actual level in different aspects of digital literacy of our young investigators. Part 3.2 will then list our findings in the area of the computational competencies and 3.3 in the area of the social competencies.

\section{Choosing proper digital technology and tool}

When students were working on the open-ended problems they had to decide, which tool to use to solve it. They were learning quickly and easily from each other what tool to use for what purpose.

- Every team member worked on his or her own computer where he or she could use all available programs. One of the team members with lower degree of the digital literacy did not know in particular situation where to take notes (as he did not have a sheet of paper). Another member of the team suggested to him to open standard MS Notepad and take notes in it ${ }^{10}$.

- Those members of the investigation team who were not in the same room during the activity decided to communicate with each other locally through Skype. To make such communication possible, some had to install the program into their computers and then - in a very short time - to learn how to use it.

\section{Locating, interpreting, analyzing and processing information}

During every activity the students had to analyse and synthesize different kinds of information. We expected them to spot certain clues, suggestions or indications in the messages and data, which we provided to them.

\footnotetext{
${ }^{9}$ To realize this just think about scores of different concepts, terms and techniques we use when for example working with a bitmap graphics editor: choosing a tool, choosing a colour, choosing the thickness of a line, clicking with mouse, dragging, selecting an area, moving the area or copying it, changing the size of the window, inserting text, choosing the position for the text, moving it to a different place, changing the size of the selection (proportional or not), choose the font type, font size and tenths of others.

${ }^{10}$ As we will see later in 3.2 , the student finally decided to open an empty text message in his mobile phone and took notes there.
} 


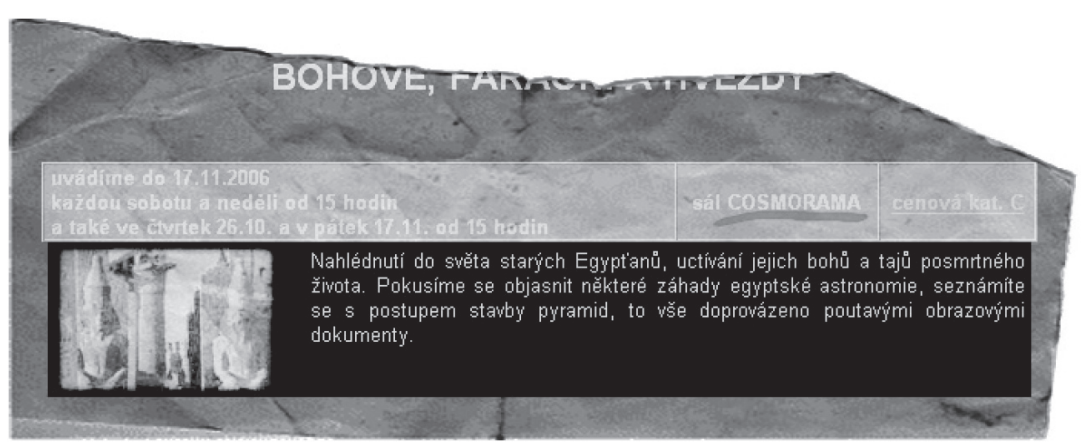

Fig. 2. A clue in the investigation: a scrap of paper with partial information.

- Students received an excerpt from a text in an unknown language (actually, in Finnish). They had to find out what language it was. They searched the Internet for the same words as they found in the unknown language and finally came to a web page with the country code domain .fi. After this they classified the unknown language to be Finnish.

- Young investigators inspected the Internet databases for various information, e.g., they searched the website of the Slovak Post Office to find the zip code of particular city in Slovakia etc.

- They had to locate various objects on the Internet maps, e.g., they searched for the name of the school according to its location on the map (they knew the street names of the junction where the school was located).

- They had to sort the biggest Slovak cities according to the number of their inhabitants (and prior to that they had to find correct web sources with required data).

- From partial information they had to assemble proper key words for the Internet search engine: A scrap of paper with some information on it had been found by the police at the scene of the crime (see Fig. 2). Based on this paper they had to start their search and make a step forward in the investigation.

- They had to prove or disprove the statements of suspicious persons or witnesses based on the information from the Internet databases. For example, in an information system of a bus company they could check whether a person's assertion was true or not. In the booking system of a flight company, they had to find the earliest possible connection between two European cities. Some teams verified their findings also with other flying companies (however, we observed such thorough behaviour very rarely. More frequently, we observed the opposite, i.e., accepting certain finding without careful checking or considering, see 3.3).

\section{Communicating through diverse channels}

Students experienced communication through various information channels, in particular, e-mails, websites and tools for chatting.

- During the investigation, they were often receiving messages from the police headquarters. Sometimes they communicated with each other through e-mails (in cases when they had to exchange information between each other). 
- In each investigation they worked in a portal system ${ }^{11}$ to which they had to assign, register for an on-line game and fill in various forms. For every investigation, we created a unique new website. We were purposefully changing the game registration forms so that the students had to orientate in a new environment, read the information and instructions carefully etc.

- Some of the teams used the Internet not only for information searching or communicating with the headquarters, but also for communicating with other team members.

"I emailed the tasks to other members of the team. We distributed them among us, then discussed the results on Skype first, then I emailed them to Police head office" (Hlina team of investigators).

\section{Perfecting efficiency in applying digital technologies}

Repeated engagement in investigative problem solving led students to higher proficiency and more efficient work with already known or even unfamiliar digital technologies.

- Students who had had the experience with previous investigative activities could orient faster in the new problems than those taking part in the investigations for the first time.

Synthesizing information and deepening understanding of digital technologies

Students had to apply their general overview of commonly used hardware, its functionality and prices. Such opportunities appeared during the investigations like the following one:

- When thieves had broken into the school's computer laboratory and had stolen different personal computers and other hardware items, the investigators had to estimate the overall financial loss because of the negotiations with the insurance company.

\subsection{Computational Competencies}

The research of the computational competencies is particularly significant for us, because it helps us better understand what function, form and structure the informatics as an academic subject at primary and secondary school stages should have. It also helps us to specify educational goals for the informatics and ICT curriculum itself, thus get incentives about the general directions of this field's development at schools. Observations and findings resulting from this and other ongoing research projects in the field of technology enhanced learning help us for example in developing interactive interfaces for learning, see (Kalas and Winczer, 2006), or in developing new teaching/learning strategies for modern informatics ${ }^{12}$ (Kalas and Winczer, 2008).

\footnotetext{
${ }^{11}$ Based on www . joomla. org.

${ }^{12} \mathrm{We}$ mean informatics as a moder, constructionist learning opportunity for everybody - for every girl and boy.
} 
We also profit from these results when we plan and design the in-service teachers' development or when we design and organize various contests focused on promoting interest in digital technologies and informatics for all students. At present, probably the most successful and influential event of this kind in European countries is the Bebras competition (Dagiene, 2006; Dagiene and Futschek, 2008). When we analyzed the results of Slovak schools involved in the contest in 2008 (Kalas and Tomcsanyiova, 2009) we suggested the following classification of the components of the informatics education: (i) digital literacy, (ii) programming, (iii) problem solving, and (iv) data handling. In this part of the paper we will document the students' performance at solving those tasks which characterize the level of their competencies in problem solving, data handling and partly also in programming components - altogether we named them computational competencies.

\section{Advanced data handling}

In many problems, which arose from the investigation activities the students had to restore partly destroyed or somehow coded data.

- They received digitalized, yet partially damaged sound record. The task was to find the way for working with this sound, to investigate what kind of damage was it and then try to repair it so they could get its content (the clue was the sound track was reversed).

- The investigators received by e-mail a bitmap file with a hidden password. However, the password was illegible, written in almost the same colour as the background (the difference between the two colours was just one point in their RGB colour codes). After filling the background of the image with any random colour, the important password was suddenly revealed, see Fig. 3.

- During the activities the students had to find out some important information about received data, like what kind of camera was used to take that particular photograph, what is the size of the corresponding file, what is the exact size of the picture, when exactly was it taken etc.

- In order to advance in their investigation, the students had to compare two seemingly identical pictures, see Fig 4 . They could make use of any image editor to find the differences and describe them in detail.

- The investigators received a sound file, which contained a message in the Morse code. First, they had to convert it into a graphic image file with the message in the Morse code, see Fig. 5, then decode it.
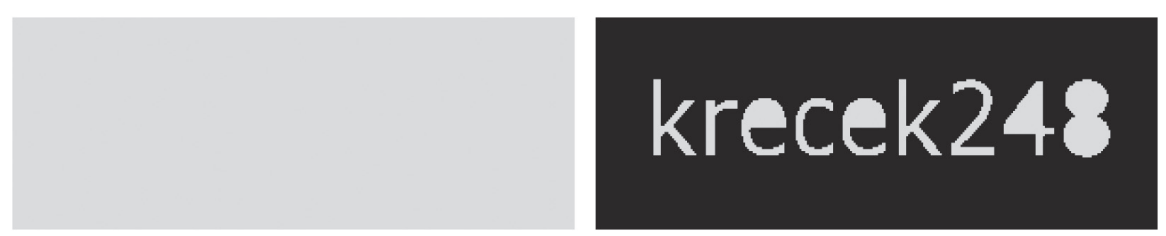

Fig. 3. The bitmap picture the investigators received (on the left) and the password it finally revealed (on the right). 


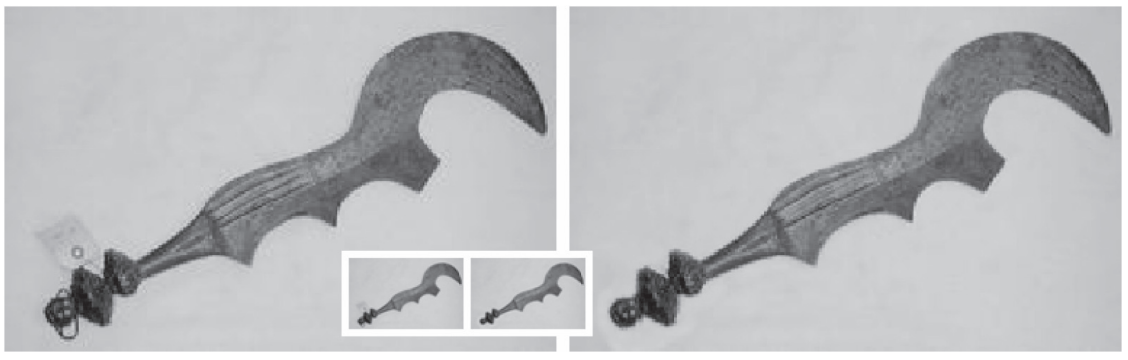

Fig. 4. Two identical pictures (at least at first glance). Hint to spot the difference: compare the shapes of two curves in the middle part.

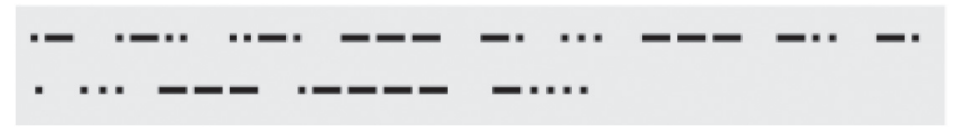

Fig. 5. Graphic file with Morse code message.

Let us quote from the video record analysis of an investigation of the F.B.I. team:

... Peter, probably the most skilful investigator of the team, started to solve the Morse code task. Before others became aware of the key point of it, he was already transcribing the sound record into the letters. It was interesting to observe him giving the advice to a team mate who had no paper to note the letters: "Why don't you open a text editor and write it right there". Finally, instead of opening the text editor the other guy opened a new text message in his mobile phone and started to put down the letters there...

Peter managed to find a Morse code table on the Internet and started to dictate the sequence letters to others. In a moment, Juraj, Tomas and Lucia run up to him to find out, which web page did he find and how was he proceeding.

\section{Applying common software tools in advanced and creative ways}

Students actively and creatively applied general software tools like graphic editors, text processors, sound recorders etc. During the investigations they had to accomplish following tasks with the help of these tools:

- Modify a photograph by using graphic editor for later use in the investigation.

- Create a picture negative.

- Find a corresponding colour according to its RGB representation.

- Rearrange the order of isolated pictures based on the inherent logic of the whole sequence, for example, arranging the steps of tying a knot, (see Figs. 6 and 7). We consider this cognitive operation to be an opportunity for developing algorithmic thinking - students had to understand the steps of the process and rearrange them in correct order. At the same time, the task was an occasion to present the ability to work with graphic software tool by composing a new image from its parts saved in several files. 


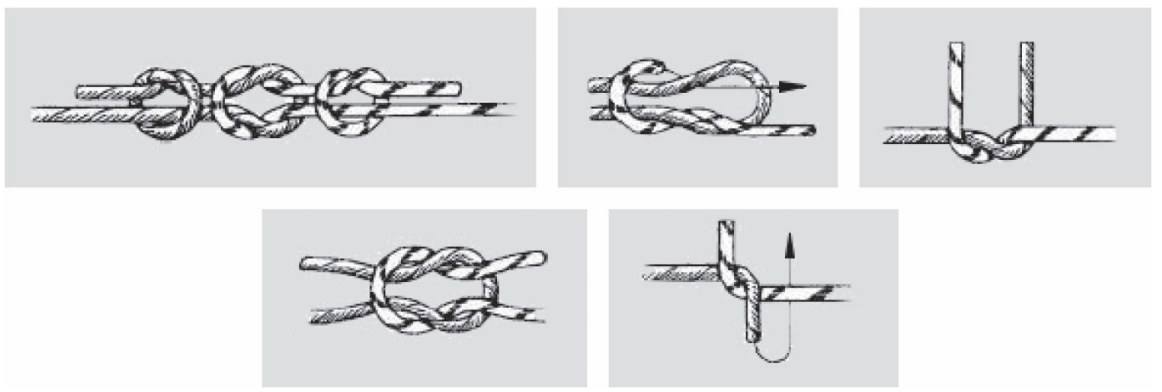

Fig. 6. Each single picture saved in a separate file.

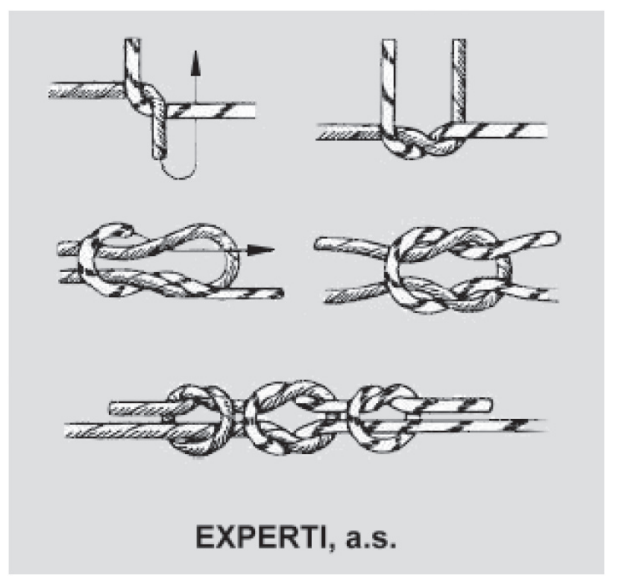

Fig. 7. The final sequence of pictures saved in one file.

- Modify a picture in graphic editor, transform it vertically, highlight or analyze its details.

- Work with a text editor. In one investigation, the text was written all in white font colour in a document with white background, so the investigators had to find out where the information is at all, and then modify the text to be visible and readable.

\section{Applying previously unknown software}

The students had to use special programs during the investigations; they had to find, download and install such software into their computers and then use it - even though it was completely unknown to them, with new and non-standard control items and functionality. During the investigations, the young detectives had to:

- Find a special program for recovering deleted data from their hard disk.

- Explore and employ various Imagine Logo microworlds, see for example Figs. 8 and 9. We sent them a microworld without any help or description. Usually they had to use it to play a game, which helped them solve a partial problem. We consider such challenges an opportunity to develop creative and exploratory learning. 


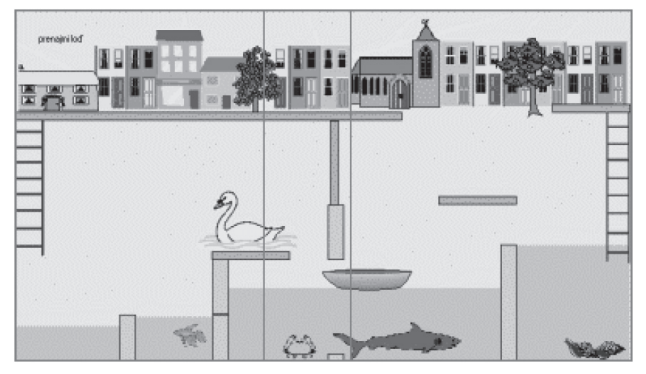

Fig. 8. Imagine Logo microworld: a game to cross the Canal Grande.

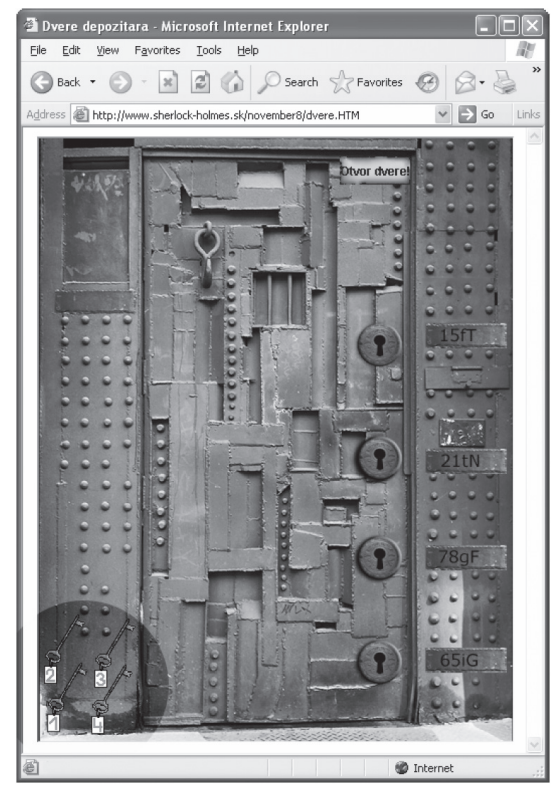

Fig. 9. Another Imagine Logo microworld: How to get inside the museum depository.

- Use a complex software application developed in Delphi Pascal. The application was created especially for the investigation, so the students did not know it and had not use it before - its purpose was to reveal some partial tasks to be solved and thus continue the investigation.

\subsection{Social Competencies}

The most complex and creative types of problems the teacher can mediate to students are problems, which require:

- analysis of a situation and synthesis of its partial solutions (especially when the situations are vaguely defined or open-ended),

- formulation of arguments supporting methods which students have applied,

- creativity and critical assessment of situations and solutions,

- consideration of several alternative procedures, methods or arguments.

We intentionally designed and developed the investigative on-line activities in such a way that one student would not be able to solve it because of the amount of effort and time required. So the students could succeed in the investigations only by a well organised team work, appropriate distribution of partial problems, good coordination of procedures and high efficiency in communicating - within the group or with "external helpers" (for example their parents, friends etc.) and with the police headquarter. Thanks to this principle we created a unique opportunity for observing the process of how the team work gradually emerged, how the teams gradually improved their coordination and manage- 
ment, how the team members were learning while playing their roles in the activity, peer to peer collaborative learning or learning on demand, which forms of communication they applied and how effectively did they apply and many other interesting social interactions.

\section{Emerging collaboration within the teams}

At the beginning, instead of effective task distribution of the work among the team members the students usually relied on spontaneous and self-organizing progress in the problem solving. Although there was a supervising teacher present in the room during their investigations, he did not take part in the working of the team. However, this was what the students expected to happen and what they usually experience at schools. We observed the following phenomena:

- When we asked the team members right after an investigation to classify the roles of each member, they labelled somebody else as a leader of the group than the one we later identified as a leader from the corresponding video records.

- There was obvious lack of coordination of the sub-tasks distribution and cooperation.

- Students solved the partial problems of a complex task very well, but had difficulties to combine solutions of the subtasks into one aggregated result.

- Several members of the same team individually managed to find a traffic connection from town A to town B, but they were not able to come to a consensus about which of their findings to send to the headquarters.

Even though the collaboration in the teams started at a low level and was initially rather chaotic, gradually - during the activity and even more from one activity to another - was improving and getting more efficient.

It was evident, that the members of the F.B.I. team did not have much experience with cooperation. During their first investigation, Peter was assigned the role of the leader, but he did not control the work of the team at all. Everybody was processing the same mails and waiting for new messages. When they received an e-mail, somebody shouted out:

"I will look for a city in Finland!", but was immediately stopped by other team member: "I am already looking for it! Try to do something else!"

After several initial e-mails they started to work together, for example by creating a theory of how the precious jewel was stolen. The F.B.I. team proceeded at every new investigation more systematically and distributed the tasks more effectively. During the second investigation (several weeks later), we observed how one of the team members read out loudly new information about a clay statue and others were carefully listening to her. After that they agreed together on the next investigation steps.

- Following message from the investigators illustrates the level of efficiency of the team's cooperation:

"When we received the task, there was a chaos, but a bit later one after another we started to shout out what would be searched by whom... When we finished we were either chatting or fighting over a white board marker or eventually we made a summary of given tasks..." (Vazkári team of investigators). 


\section{Collaborative learning within teams}

During the activities we often observed an effective and fast learning from each other, i.e., peer-to-peer collaborative learning. It was highly impressive how quickly and effectively the students could transfer their knowledge between each other, exactly in terms of Vygotsky's theory of social constructivism (Vygotsky, 1978). It happened exactly at the moment, when they needed it and when their motivation was the highest.

- Within the first investigation students had to fill in a form and send it back to the "police headquarters". Two members of the F.B.I. team, however, had difficulties with saving and sending the form as attachment - the others immediately rushed to help them.

- The standard decompression of files caused problems to some of the team members at the beginning. Nevertheless, a member of another team sent them an advice:

"You have to unzip it first. First select all the files, press CTRL and A, click Start and extract the files, then Finish!"

- Lucia wanted to explore a detail of a picture, but did not know how to do it. Martin came to help her:

"Highlight it, select an area and click in it."

Later Juraj did not know how to create a negative from a picture, so Barbora came and showed him the method.

\section{Creativity of students}

Creative collaboration within the team often resulted in unconventional solutions, which could rarely be observed at school (as far as students are not encouraged to such methods). The creativity of the students often emerged in problems and tasks, in which we did not provide them with any hints, any help or any directions to solution.

- Students had to create a postcard, which would somehow characterize their investigative team and all its members. Due to the fact that we did not show them any examples of similar postcards, we received many impressive proofs of their creativity, see, e.g., Fig. 10. We even received a coded postcard from one team, so that "Sherlock Holmes" himself had to decode the cipher to be able to read it.

Traditional school puts the students in the position of information receivers and only rarely they are expected to perform unconventional creative thinking.

- We asked young detectives to label the positions they occupied in the teams during the investigation and we gave them several examples. Nearly all of the teams used literally the words used in our examples, or very close alternatives. Only rarely the students made up their own creative descriptions of the positions in the teams.

\section{Self assesment}

Students, who claimed in the initial survey to had reached high level of digital literacy, often overestimated their real skills. Sometimes we observed them having difficulties in navigating an unknown though trivial application environment; some students asked for help the other team members - sometimes in surprisingly elementary situations.

- Already in the first investigation students were asking each other some quite trivial questions while solving the tasks, which required rather basic informatics skills. 


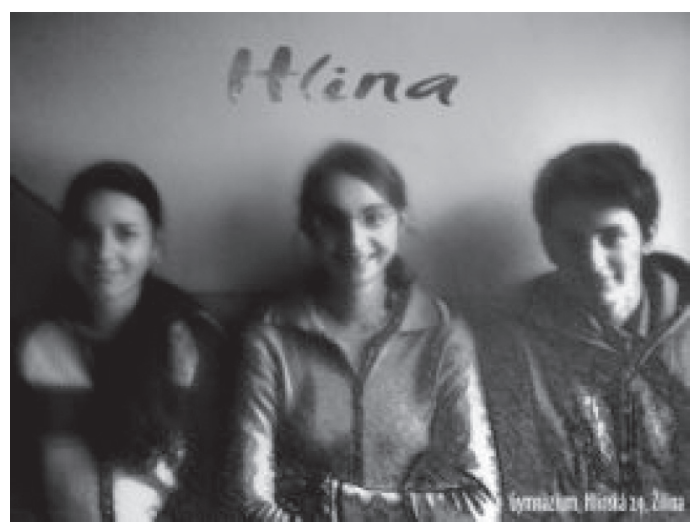

Fig. 10. Postcard from the Hlina team of 3 members.

Yet in the survey, they had assessed themselves as digitally literate and highly skilled.

We were highly interested in how the students would assess the performance of the other members of their teams and how they would evaluate their own methods during investigations. We consider it extremely important to develop those metacognitive skills of students in the digital environments.

- The team members described the distribution of the roles among them as follows:

"Well, he is simply our brains. He decides what to do and we eagerly start to work on it."

"Her task is to put down all important information, reply to e-mails and beside that write down the final report - we like to use her keyboarding."

"Officially, he is appointed to search for information on the web - he is the best at it. He is always able to find all important things before I have even finished reading the instructions. It could be because he reads a lot, many books - not only in our language. He reads at the breakneck speed."

"He definitely doesn't lack logic and common sense - he processes all obtained information and tries his best to anticipate the criminal, to uncover even the smallest contradiction in the evidence. He helps everybody and anywhere we need."

(All of these quotations come from the Ickari team of investigators.)

\section{First thought is sufficient}

We noticed that the computer activities presented substantial temptation for students to get satisfied with their first quick solutions (or even semi-solutions). Instead of looking for properly verified clarifications, they preferred the very first indication of a solution. After this happened they rarely thought of any other alternative solutions or inconsistencies with newly revealed information. They do not realize that the problem solving should involve some analysis, testing and going back to rethinking other possibilities until the solution fulfils all the conditions given by the initial settings of the task. 
- When searching for a bus connection between two cities they were satisfied with the first result, even though they knew the cities were quite close and (according to their findings) the travelling would take more than 4 hours. They wrote about their solution:

"This bus route is strange, but this is what we found."

- The students had to find the name of a small French town - based on the Latin name of a particular fish. Students were satisfied with a partial solution and did not try to complete it.

- Here is the video record analyses of an investigation of the F.B.I. team:

$\ldots$ in the instructions they were asked to find out for how long Anna and Julia did not meet. (The investigators knew that for the last time the two girls met on the premiere of The Garden movie, therefore they had to find out when that was.) After reading the e-mail, silence fell in the room. After a while, Lucia came up with the idea to find out when the film was on. After that, every member of the team continued his or her work; some searched the web for that information. Barbora came back with the result as the first one and said: It was played in 1997, so they haven't met for nine years! Some of the investigators had not even managed to read the instructions so far, because they were still filling in the initial questionnaire. Thus, Barbora easily persuaded everybody that her solution was correct and sent the answer to the headquarters. Nobody in the F.B.I. team checked it anymore. However, it was wrong.

\section{Solving complex problems}

Often the students did not read the given problem carefully and therefore tried to solve slightly different task or did not think about each given fact or constraint provided in the problem assignment. We submitted every task intentionally in the form of a story, as far as we agree that. . the ability of problem solving is related to the level of reading literacy, (PISA Report, 2003). When solving similar tasks, it is not only the level of digital literacy and computational skills, which are involved, but also other cognitive skills like understanding the text, searching for information, analyzing the input facts and synthesising obtained results.

- The students had problems mostly with those types of tasks, which were not clearly defined and expected them to creatively interpret the text.

- The team of investigators named Kojakovia (the Kojacs) correctly identified the criminal in disguise among the passengers on the plane (see Fig. 11), but did not understand properly the way the seats in the plane were labelled so they failed that task.

- The students could not succeed in solving the problem because they were not able to summarize all the obtained and discovered information about the problem although they possessed all needed bits. 

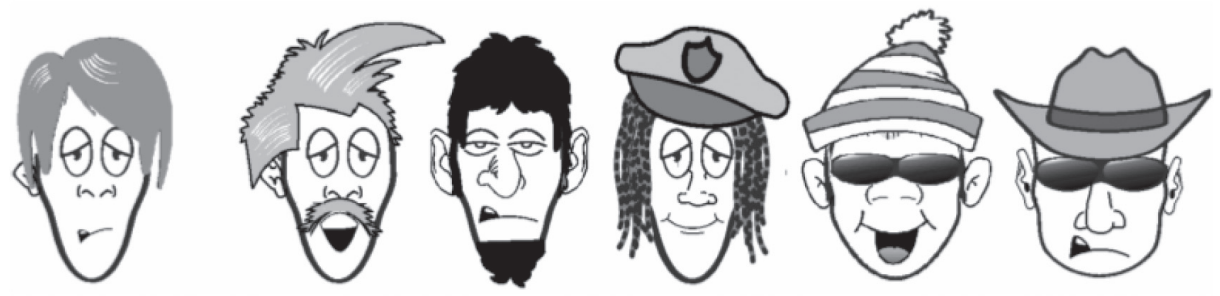

Fig. 11. The criminal (on the left) and a group of suspects from the investigation, one of them is the criminal in disguise.

\section{Final Considerations}

We had twofold goal in our reported research project: (A) to study the potential of the Internet and on-line activities in terms of building students' computational skills, digital literacy and social competencies at lower and upper secondary stages; (B) to create and iteratively develop a learning environment to mediate this potential to young people. To achieve this double goal we iteratively created the Sherlock Holmes portal, see www.sherlock-holmes.sk, through which we implemented a series of investigative on-line activities to real school settings. From the year 2000 to 2008, we put in practice our activities and achieved great interest of the students and their teachers. Throughout the on-line investigations, we built a virtual research laboratory, which enabled us to observe students while they were conducting collaborative teamwork to find solutions to interesting tasks in attractive digital environment and by using attractive software tools. After every activity we evaluated our observations and reflected on necessary changes to further improve following activities. The aim of these changes was to have our activities better oriented to developing the observed skills and competencies. Every new activity and every new analysis of the observed phenomena helped us to deepen our understanding of the educational potential of the Internet to support modern constructionist approach to cognitive processes. We applied the design-based research strategy to fulfil our goals, moving in the spiral iterations, see Fig. 12.

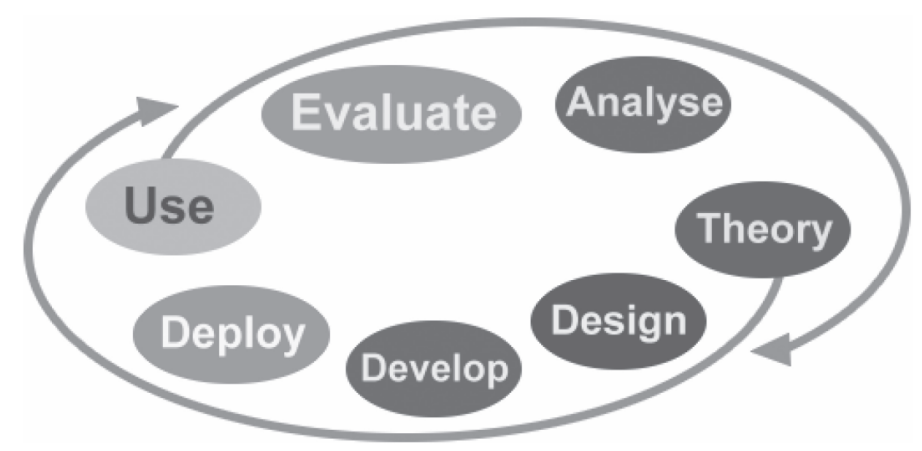

Fig. 12. Interwoven streams of theoretical educational research and intervention iterative design (see Design-based research portal at www. $1 \mathrm{kl}$. ac.uk/projects/designresearch). 


\subsection{Teachers' Statements}

As we have already mentioned before, every team had a teacher present during the activity. The teachers' role was only to monitor the team; they did not get involved in any problem solving process. They even did not organize the work or lead the teams. In some way, they were present only as additional unplanned non-participant observers of the investigation and of the teamwork. To learn from their observations, we decided to collect teachers' comments and suggestions and analyze them as well. Here we present some of the comments to illustrate how influential event for schools and opportunity for students the investigative on-line activities were, see also Figs. 13 and 14.

This competition is excellent. I was overwhelmed when I saw the atmosphere in the group, cooperation inside the team. The students draw the situation on the board, marked relationships and obtained information. In the classroom, it looked like in a thrilling detective story. When they were arguing about the results and drawing the evidence on the board, it was visible how the students got motivated by the competition and how they lived their roles (teacher of a grammar school in Bratislava).

The competition motivates students to cooperation; people with good combinative and logical thinking are demanded! I appreciated that they were using many different
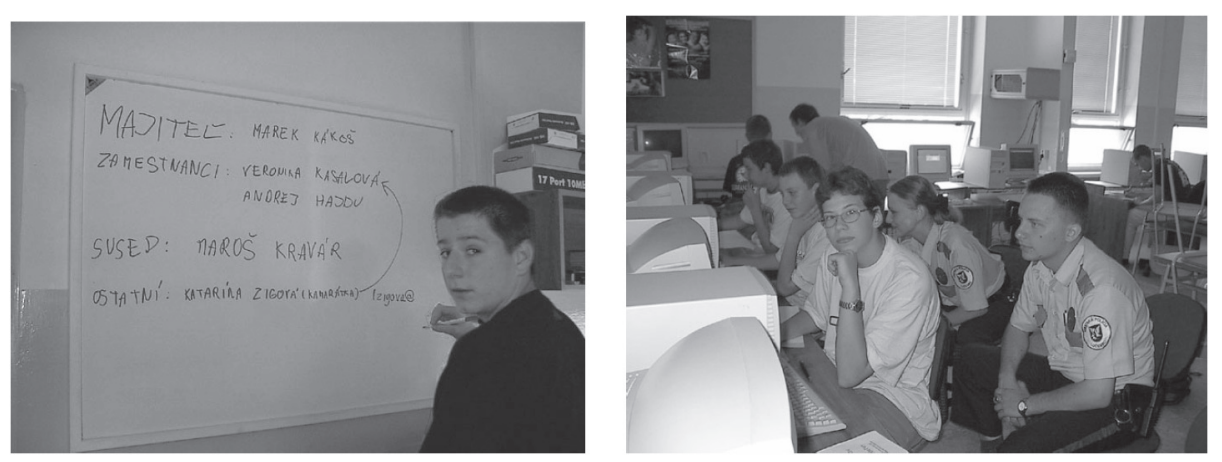

Fig. 13. Immersed in investigation. Some schools invited real police officers to make the event more realistic.
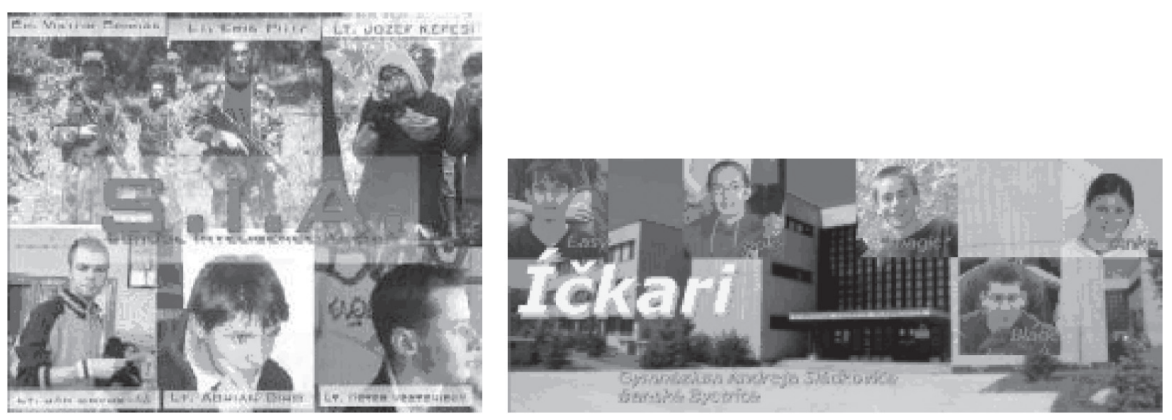

Fig. 14. Self presentations of some of the teams. 
technologies (like e-mails, graphics, or data encryption - until you sent decoding program the children came up with a code themselves..., sound etc.) (teacher of a grammar school in Snina).

In the room where the teams were located, there was an intense working atmosphere. The students argued a lot but more often they supported each other and were ready to cooperate. In many classes the cooperation is not appreciated or, better expressed, is forbidden, so this was something new and interesting. As a plus I take already mentioned cooperation, division of tasks - where everyone carried responsibility for some activity. For us - teachers, a big bonus was that even though our school is focused on programming and informatics, unfortunately not every student is able to participate in a competition for programmers. And here, the students who are great "technicians" but weaker programmers got the opportunity. We are happy that such competition exists and we were able to provide more children with this opportunity (teacher of a grammar school in Nitra).

\subsection{Summary of the Main Observations}

Here we list the main results of our observations:

- Students usually overestimated their initial digital competencies and abilities. We assume this was happening because of their narrow comprehension of what digital and computational literacy is - students usually reduce these competencies only to capability to communicate by e-mail and to search web for information. On the other hand, they have the capacity - when challenged with proper motivation - to enlarge their digital techniques and knowledge easily while working with technologies. As a confirmation of this statement, see the next bullet.

- While working on partial problems and striving to come to important conclusions students often employed various (even non-trivial) computational methods. If somebody from the team did not understand the applied method, another member of the group run to help and taught him or her how to use it. We observed several examples of such lively and effective team learning moments.

- During the investigations, students were usually reading the tasks together and were questioning each other in case someone did not understand any point clearly. If the task was too complex they split it into smaller problems. After completing the partial tasks they tried to combine the solutions into one result. At the latter stage of synthesizing the partial solutions together, students often encountered serious problems. However, from one investigation to another this process was getting more efficient and successful.

- Students often asked their parents or friends, who were not taking part in the activity, for help. Usually they called them by mobile phones, sent them e-mails or reached them through a chatting tool (such strategy did not breach the rules of the investigations). It usually happened when students were solving problems of every-day life. Suddenly they recalled, that someone from their family or a friend recently encountered similar problem in his or her life. 
- We observed that during the investigations students were more successful when solving well defined and clearly stated problems and far less successful with nontransparent open-ended tasks. In such situations, they had to identify the problem to be solved, reveal several connections and associations, find their own strategies, exclude certain approaches, and consider several arguments or alternatives, perform analytical, analogical or combinatorial reasoning, which jointly constitute centre of the problem solving competencies.

- Students could not rely on the authority and knowledge of their teacher during the investigation. It was their responsibility - and opportunity - to decide what are priorities for the moment, which information is important and relevant right now, which strategy to choose, which notes to take and which facts neglect.

- During the teamwork, the members had to collectively decide who would deal with which task. This process was at the beginning highly chaotic and spontaneous. Only later, in their second or third investigation they started considering who of the teammates was more suitable for certain tasks, they started thinking about their own skills and also of every team member's abilities and strengths. According to the students' own statements (as we illustrated in Section 3.3), they took these considerations seriously and responsibly.

\section{Conclusions}

We assume that through designing, developing and conducting the investigative on-line activities we not only create attractive opportunities for lower and upper secondary students to employ educational potential of Internet in a complex way, neither we only provide them with productive learning environments for developing their digital, computational and social competencies, but we do more. We also:

- facilitate the development of general problem solving skills of our students. During the investigations they were faced with the problems they had never seen nor practiced before in any school subject,

- develop supplementary strategies for building modern constructionist informatics education $^{13}$,

- employ digital technology to open new directions for learning - project-based, immersion learning compatible with the Caperton and Papert's vision for education, see (Caperton and Papert, 1999),

- demonstrate - not only to students, but to their teachers and parents as well, which are new possible alternatives to utilize digital technology for modern learning, which are new attractive forms of projecting the learning process.

\footnotetext{
${ }^{13}$ As we discussed it in (Kalas and Tomcsanyiova, 2009).
} 


\section{References}

Caperton, G., Papert, S. (1999). Vision for Education - The Caperton-Papert Platform. National Governors' Association, Missouri.

Cobb, P., Confrey, J., diSessa, A., Lehrer, R., Schaube, L. (2003). Design experiments in education research. The Educational Researcher, 32(1), 9-13.

Dagiene, V. (2006). Information technology contests - introduction to computer science in an attractive way. Informatics in Education, 5(1), 37-46.

Dagiene, V., Futschek, G. (2008). Bebras international contest on informatics and computer literacy: Criteria for good tasks. In: Mittermeir, R.T., Syslo, M.M. (Eds.), Informatics Education - Supporting Computational Thinking, ISSEP 2008. LNCS 5090. Springer, Berlin Heidelberg, 19-30.

DBR Collective (2003). Design-based research: An empirical paradigm for educational inuiry. The Educational Researcher, 32(1), 5-8.

Gilster, J. (1997). Digital Literacy. Wiley and Computer Publishing, New York.

Harel, I., Papert, S. (1991). Constructionism. Ablex Publishing Corporation. Norwood, NJ. Ablex Publishing Corporation.

Jones-Kavalier, B.R., Flannigan, S.L. (2006). Connecting the digital dots: Literacy of the 21st century. Educause Quarterly, 8-10.

Accessible from net. educause. edu/ir/library/pdf / EQM0621.pdf (15 March, 2009).

Kalas, I., Winczer, M. (2006). Building interfaces for on-line collaborative learning. Education and Information Technologies, 11(3-4), 371-384.

Kalas, I., Winczer, M. (2008). Informatics as a contribution to the modern constructivist education. In: Mittermeir, R.T., Syslo, M.M. (Eds.), Informatics Education - Supporting Computational Thinking, ISSEP 2008. LNCS 5090. Springer, Berlin Heidelberg, 229-240.

Kalas, I., Tomcsanyiova, M. (2009). Students` attitude to programming in modern informatics. Accepted for the IFIP World Conference on Computers in Education, Bento Goncalves, Brazil 2009.

Lambert, M. (2002). 21st century learners - and their approaches to learning. In: School of Education, University of Wolverhampton, UK.

Accessible at ultibase.rmit. edu. au / Articles / sept 02 / lambert1. htm (March 2009).

Mor, Y., Winters, N. (2007). Design approaches in technology enhanced learning. Interactive Learning Environments, 15(1), 61-75.

PISA (2004). Problem Solving for Tomorrow's World, First Measures of Cross-Curricular Competencies from PISA 2003. OECD, France.

Rethey-Prikkel, B., Turcsanyi-Szabo, M. (2003). Team challenge. In: Proc. of EuroLogo Conference, Porto, 281-290.

Resnick, M. (2007). Sowing the seeds for a more creative society. Learning and Leading with Technology (ISTE's membership magazine), December/January 2007-08, 18-22.

Tapscott, D. (1997). Growing up Digital. McGraw-Hill, New York.

Vygotsky, L. (1978). Mind in Society. Harvard University Press.

Wang, F., Hannafin, M.J. (2005). Design-based research and technology-enhanced learning environments. Educational Technology Research and Development, 53(4), 5-23. 
Z. Galik obtained PhD degree in the field of informatics education in 2008 at Comenius University in Bratislava (Slovakia). He was working between 2003 and 2009 at the Department of Informatics Education as a researcher and teacher. He received his master degree at the same university in 2002. His main research interest is the Internet as a learning opportunity and creating and searching for productive ways of using on-line educational activities in the process of learning. Prior to starting his PhD studies he was working as a mathematics' teacher at a public school in England.

I. Kalas is a professor of informatics and informatics education at Comenius University, Bratislava and head of the Department of Informatics Education. His interests include development of constructionist educational interfaces for learning for children and research in the field of the impact of digital technology on learning - TEL (Technology Enhanced Learning). Ivan is co-author of several programming environments for children, including SuperLogo, Imagine Logo, Thomas the Clown and RNA (Revelation Natural Arts) adopted by thousands of schools, home and abroad. He is also an author or co-author of several books and textbooks on children programming and informatics, which have been published in several languages and countries in Europe and beyond. He has also been active in several national policy efforts and programmes, among them highly influential Infovek project. Recently, he has been appointed guarantor of Slovak national informatics teachers development programme. Ivan represents Slovakia in the IFIP Technical Committee for Education. Since 2008, he is a member of the International Advisory Board of the Microsoft Partners in Learning initiative. Ivan lives and works in Bratislava.

\section{Skaitmeniniu, kompiuteriniu ir socialiniu kompetenciju ugdymas naudojant tiriamąsias interneto veiklas}

\section{Zoltan GALIK, Ivan KALAS}

Internetas ir jo paslaugu veiklos tapo neatskiriama jaunuomenès gyvenimo dalimi. Nepaisant to, interneto galimybės mokyme yra tik iš dalies pripažintos ir išnaudotos. Noredami išsiaiškinti šiu trūkumų priežastis keletą metų stebejjome Slovakijos mokinių grupę: kaip jie naudodamiesi technologijomis sprendžia iškilusiais mokymosi problemas, kaip bendrauja ir bendradarbiauja grupèse, kokių igūdžiu igyja. Šiame straipsnyje pateikiamos pradinès stebejimo prielaidos, tyrimo metodai ir eiga, aiškinama kas yra tiriamosios interneto paslaugos, kaip buvo renkami ir analizuojami duomenys, gauti stebint užduotis atliekančius studentus. Nagrinejjamos trys kompetencijų klasės: skaitmeninè (kas yra susiję su skaitmeniniu raštingumu), kompiuterinè (kas atitinka informatikos mokymo tikslus) ir socialinè (kas leidžia studentams bendrauti, bendradarbiauti, kurti ir vertinti savo darbą, mokymąsi ir kt.). Straipsnyje pateikiamos mokytoju - nepriklausomu ekspertu - pastabos ir išvados, aprašoma šio tyrimo nauda šiuolaikinei mokslo visuomenei. 